\title{
Attaining the canopy in dry and moist tropical forests: strong differences in tree growth trajectories reflect variation in growing conditions
}

\author{
Roel J. W. Brienen · Pieter A. Zuidema • \\ Miguel Martínez-Ramos
}

Received: 28 January 2009 / Accepted: 4 December 2009 / Published online: 24 December 2009

(C) The Author(s) 2009. This article is published with open access at Springerlink.com

\begin{abstract}
Availability of light and water differs between tropical moist and dry forests, with typically higher understorey light levels and lower water availability in the latter. Therefore, growth trajectories of juvenile trees-those that have not attained the canopy-are likely governed by temporal fluctuations in light availability in moist forests (suppressions and releases), and by spatial heterogeneity in water availability in dry forests. In this study, we compared juvenile growth trajectories of Cedrela odorata in a dry (Mexico) and a moist forest (Bolivia) using tree rings. We tested the following specific hypotheses: (1) moist forest juveniles show more and longer suppressions, and more and stronger releases; (2) moist forest juveniles exhibit
\end{abstract}

Communicated by Brian Beckage.

Electronic supplementary material The online version of this article (doi:10.1007/s00442-009-1540-5) contains supplementary material, which is available to authorized users.

R. J. W. Brienen · M. Martínez-Ramos

Centro de Investigaciones en Ecosistemas,

Universidad Nacional Autónoma de México,

AP 27-3 Santa María de Guido, CP 58089 Morelia,

Michoacán, Mexico

P. A. Zuidema

Ecology and Biodiversity, Utrecht University,

PO Box 80084, 3508 TB Utrecht, The Netherlands

R. J. W. Brienen · P. A. Zuidema

PROMAB, Casilla 107, Riberalta, Beni, Bolivia

R. J. W. Brienen ( $\square)$

School of Geography, Ecology and Biodiversity,

University of Leeds, Woodhouse Lane,

Leeds LS2 9JT, UK

e-mail: roelbrienen@ hotmail.com wider variation in canopy accession pattern, i.e. the typical growth trajectory to the canopy; (3) growth variation among dry forest juveniles persists over longer time due to spatial heterogeneity in water availability. As expected, the proportion of suppressed juveniles was higher in moist than in dry forest (72 vs. 17\%). Moist forest suppressions also lasted longer ( 9 vs. 5 years). The proportion of juveniles that experienced releases in moist forest $(76 \%)$ was higher than in dry forest $(41 \%)$, and releases in moist forests were much stronger. Trees in the moist forest also had a wider variation in canopy accession patterns compared to the dry forest. Our results also showed that growth variation among juvenile trees persisted over substantially longer periods of time in dry forest ( $>64$ years) compared to moist forest (12 years), most probably because of larger persistent spatial variation in water availability. Our results suggest that periodic increases in light availability are more important for attaining the canopy in moist forests, and that spatial heterogeneity in water availability governs long-term tree growth in dry forests.

Keywords Canopy accession - Cedrela odorata . Gap dynamics · Growth suppression · Tree rings

\section{Introduction}

Availability of light and water varies strongly between tropical moist and dry forests (Murphy and Lugo 1986; Holbrook et al. 1995; Coomes and Grubb 2000). In tropical moist forests, light availability is very low for seedlings and saplings in the forest understorey, while canopy trees receive full light (Turner 2001; Poorter et al. 2005). Low light levels strongly limit sapling growth ("suppression"), and may last for decades (Chazdon and Fetcher 1984; Clark 
and Clark 1999; Brienen and Zuidema 2006). As a result, saplings of many species require periods of increased light (gaps) in order to reach the forest canopy (Denslow 1980; Brokaw 1985). Such high-light periods are probably responsible for the fast growth intervals ("releases") that are typically observed in diameter growth trajectories (Brienen and Zuidema 2006; Baker and Bunyavejchewin 2006). In tropical dry forests, on the other hand, understorey light levels are relatively high, due to a more open and lower canopy compared to moist forests (Holbrook et al. 1995; Murphy and Lugo 1986; Coomes and Grubb 2000). As a consequence, sapling growth is expected to be less limited by light, resulting in less severe growth suppressions, of shorter duration. Also, releases from suppressed growth conditions that result from gap formation will probably occur at a lower frequency in dry forests and be less strong than in moist forests. Thus, temporal variation in light levels does not strongly affect tree growth in dry forests (Fowler 1986; Nath et al. 2006). This is different for water availability, which may vary strongly among years (Bullock 1997), with important consequences for tree growth. For instance, the occurrence of periodic droughts causes strong drops in diameter growth during 1 to several years (Bullock 1997; Fichtler et al. 2004; Nath et al. 2006).

Thus, the main drivers of tree growth (light, water and nutrient availability) exhibit different temporal patterns in moist and dry forests (Fowler 1986; Terborgh 1992; Mooney et al. 1995; Nath et al. 2006). As a result, tree growth trajectories in dry forests are expected to show strong spiked year-to-year variation, while those in moist forest should reveal block-like patterns of extended periods of low growth and shorter periods of high growth (e.g. Brienen and Zuidema 2006). Apart from the differences in temporal pattern, the spatial variation in these drivers also varies between forest types. In moist forest, understorey light availability at one spot may strongly change over time due to canopy dynamics. By contrast, the spatial distribution of water (and nutrient) availability in dry forests remains relatively stable over long periods of time, as this is often related to spatial variation in topography and soil properties (Murphy and Lugo 1986; Ceccon et al. 2006; Nath et al. 2006). As a result, favourable conditions for sapling growth in moist forests (i.e. high light) are likely to change after a number of years or decades, while those in dry forests (i.e. high water and nutrient availability) are likely to persist over longer periods of time, perhaps even throughout a tree's life. This may have important implications for tree growth trajectories. Previous studies in moist forests revealed that growth differences among juveniles are maintained for some time (up to 20 years; Brienen et al. 2006), but gradually disappear as temporal variation in light availability differs among individuals (Baker and Bunyavejchewin 2006; Brienen and Zuidema 2006). In dry forests, growth differences among trees may persist over longer time intervals if water (and nutrient) availability strongly governs tree growth, and if spatial variation in these drivers persists over time. But few studies have analysed variation in tree growth patterns in dry forests so far (cf. Nath 2007).

The hypothesis that light is less important for tree growth in dry forests than in moist forests has often been proposed (Fowler 1986; Smith and Huston 1989; Terborgh 1992; Mooney et al. 1995; Baker et al. 2003a), but has not been empirically tested so far. Testing this hypothesis is difficult as it requires information on tree growth and light levels from the same species in different forest types (e.g. dry and moist forests). In addition, tree growth data should cover long time spans as suppression-release cycles typically last for decades (van der Meer and Bongers 1996; Brienen and Zuidema 2006). Here we test this hypothesis by comparing long-term tree ring data from the Neotropical canopy tree Cedrela odorata in dry and moist forest. C. odorata is highly suitable for such a comparison as it has a wide geographical distribution across multiple tropical forest types and possesses clear annual rings (Brienen and Zuidema 2005). Our specific hypotheses are:

1. That saplings experience more and longer periods of low growth (suppression) and more and stronger growth increases (releases) in the moist forest than in the dry forest.

2. That variation in growth patterns prior to attaining the canopy is larger in the moist forest than in the dry forest.

3. That growth differences between juvenile trees persist for longer time periods in the dry forest due to strong and lasting spatial variation in water availability.

\section{Materials and methods}

Study sites and species

This study was conducted in a tropical dry forest on the Peninsula of Yucatan, Mexico and a tropical moist forest in the Bolivian Amazon. Classification of forests into "dry forest" and "moist forest" follows Chave et al. (2005), and will be used from here on. The dry forest site is located in the state of Campeche, in the communal forest area of the Ejido Pich $\left(19^{\circ} 03^{\prime} \mathrm{N}, 90^{\circ} 00^{\prime} \mathrm{W}\right)$. The moist forest is located about $50 \mathrm{~km}$ south of Cobija in the Pando Department $\left(11^{\circ} 24^{\prime} \mathrm{S}, 68^{\circ} 43^{\prime} \mathrm{W}\right)$. The studied forests differ in the total amount of precipitation, length of dry season, soil type, and forest structure (Table 1; Fig. S1). In the dry forest, the terrain consists of low karstic hills with very good drainage and flat valley areas with clay and loam soils that occasionally 
Table 1 Characteristics of the dry and moist forest sites and their Cedrela odorata populations

a Sensu Chave et al. 2005

b Data 1950-2005, Comisión Nacional del Agua, Mexico

c Data 1951-2000, GHCN, http://www.ncdc.noaa.gov/oa/ climate/ghen-monthly/

${ }^{d}$ Unpublished data, L. Lopéz

\begin{tabular}{lll}
\hline & Dry forest (Mexico) & Moist forest (Bolivia) \\
\hline Forest classification $^{\mathrm{a}}$ & Tropical dry forest & Tropical semi-evergreen forest \\
Mean annual rainfall $($ min-max) & $1,100 \mathrm{~mm}(685-1,628)^{\mathrm{b}}$ & $1,700 \mathrm{~mm}(1,300-2,400)^{\mathrm{c}}$ \\
Length of dry season $(<50 \mathrm{~mm} / \mathrm{month})$ & 6 Months & $3 \mathrm{Months}$ \\
Canopy height & $15 \mathrm{~m}(10-20)$ & $30 \mathrm{~m}(25-35)$ \\
Height $(H ; \mathrm{m})-$ diameter & $H=5.6 \times \ln (D)-5.4$ & $H=8.3 \times \ln (D)-7.9$ \\
$\quad(D ; \mathrm{cm})$ relation $(D>5 \mathrm{~cm})$ & $R^{2}=0.64, n=160$ & $R^{2}=0,72, n=260$ \\
Basal area (trees $>10 \mathrm{~cm})$ & $\sim 28 \mathrm{~m}^{2} / \mathrm{ha}^{\mathrm{d}}$ & $29 \mathrm{~m}^{2} / \mathrm{ha}$ \\
Trees/ha & $900 \mathrm{Trees}^{\mathrm{h}} \mathrm{ha} \mathrm{a}^{\mathrm{d}}$ & $530 \mathrm{Trees} / \mathrm{ha}$ \\
Soil & Karstic & Xanthic Ferrosols \\
$C$. odorata & & 180 \\
Maximum diameter $(\mathrm{cm})$ & 52 & 46 \\
Maximum height $(\mathrm{m})$ & 22 & 308 \\
Maximum age $($ year $)$ & 141 & 1.1 \\
Tree density $($ no. trees $>10 \mathrm{~cm} / \mathrm{ha})$ & 4.6 & \\
\hline
\end{tabular}

inundate during the rainy season. Forest stature and deciduousness differ between hills and valleys, with higher stature and fewer deciduous trees in the latter. Terrain in the moist forest site is slightly undulating.

Our study species, Cedrela odorata L. (Meliaceae; Spanish cedar), is a relatively light-demanding canopy tree, although it does tolerate shade (Brienen and Zuidema 2006). It occurs from northern Argentina $\left(28^{\circ} \mathrm{S}\right)$ up to Mexico $\left(26^{\circ} \mathrm{N}\right)$, in areas which vary in rainfall and soil type (Pennington and Styles 1975). Cedrela trees that reach the forest canopy differ in height, diameter and age, with higher values for the moist forest (Table 1). In the dry forest, it is most abundant on karstic hill sites, whereas no habitat preference is apparent in the moist forest.

C. odorata forms distinct and strictly annual rings, as proven by cambial markings (Worbes 1999; Dünisch et al. 2002) and correlations between ring-widths and climate (Brienen and Zuidema 2005). The formation of these annual rings is induced by the annual occurrence of a dry season of 3-6 months (cf. Table 1; Fig. S1) during which the species is completely deciduous, enters cambial dormancy and forms a terminal parenchyma band (Worbes 1999; Dünisch et al. 2002; Brienen and Zuidema 2005). It is one of many tropical tree species that produces recognizable and annual growth rings (e.g. Worbes 1999; Brienen et al. 2009).

Sample collection and ring measurements

Tree ring samples in the dry forest (Mexico) were collected in 2007 from an area of $\sim 32$ ha of mainly undisturbed forest. Some patches within this area had been selectively logged $<20$ years ago at a low density ( $<5$ trees/ha), and without a noticeable effect on forest structure. We collected ten stem discs from trees harvested in 2004 (>40 cm diameter at breast height; DBH) and increment cores from 70 trees $>5 \mathrm{~cm} \mathrm{DBH}$ in two to three directions.

Tree ring samples from the moist forest (Bolivia) were collected from an area of 850 ha in 2002, just after selective logging took place. The area had not been disturbed before. We collected entire stem discs from the bases of 60 felled trees of $>60 \mathrm{~cm} \mathrm{DBH}$ and increment cores in two to three directions from 94 trees $>5 \mathrm{~cm}$ DBH. Samples were distributed evenly over diameter categories in both areas.

In both forests samples were taken at 25- to $130-\mathrm{cm}$ height. Core and disc samples were air-dried and sanded until rings were visible. We measured ring widths using a ring-measurement device (VELMEX; Bloomfield, N.Y.) and stereomicroscope, in one to three directions depending on regularity of growth around the trunk. Ring-width measurements of different radii or cores were averaged and multiplied by 2 for conversion to diameter increments. We corrected for irregular growth forms that may lead to over or underestimations of growth by calculating the difference between the summed diameter increments and actual tree diameter at sample height. A correction factor was applied to each increment value that was weighted by the maximum difference between the increments along the radii for each particular year [for details on applied methods see Brienen and Zuidema (2005)].

Samples were crossdated using COFECHA (Holmes 1982). Successful crossdating was achieved for a substantial subsample of adult trees with regular bole form and known year of formation of the outer rings (dry forest $80 \%$, moist forest 70\%; Brienen and Zuidema 2005). Trees with irregular bole form, lacking outer rings, and dead trees were excluded from crossdating analysis. Crossdating proved 
difficult for juvenile rings due to long periods of slow growth concealing common growth variation due to climate. Mean interseries correlation and sensitivity were 0.68 and 0.64 for the dry forest (1950-2005), and 0.57 and 0.49 for the moist forest (1950-2000; cf. Brienen and Zuidema 2005), respectively. These high interseries correlations are clear proof of the annual nature of the rings (cf. Stahle 1999). In both sites, ring width also correlated significantly with rainfall, confirming that rings were formed strictly annually [dry forest (unpublished data R. J. W. Brienen); moist forest (Brienen and Zuidema 2005)].

Allometry, light availability and growth-light relations

We measured DBH (i.e. $1.3 \mathrm{~m}$ ) or diameter above buttresses, and diameter at sample height. Total tree height of trees was visually estimated for standing trees (estimated precision $\pm 10 \%$ ) and measured for felled trees. We related DBH and height using logarithmic regressions (Table 1), and applied these to determine DBH on reaching the canopy (i.e. $2 / 3$ of mean canopy height; Table 1 ). This yielded DBH on reaching the canopy of 16 and $29 \mathrm{~cm}$ for dry and moist forest, respectively, which we rounded to 15 and $30 \mathrm{~cm}$ DBH (cf. Clark and Clark 1999). In both forests, these sizes correspond with the DBH at which an average tree receives substantial direct overhead light [i.e. crown exposure index (CE) of 3b, see below].

For each individual of $C$. odorata that was alive when sampled, we assessed light availability using the modified CE of Dawkins (Clark and Clark, 1992). We used the following CEs: $1=$ no direct lateral or overhead light; $2 \mathrm{a}=$ little direct lateral light, no overhead light; $2 \mathrm{~b}=$ some direct lateral light, no overhead light; $2 \mathrm{c}=$ substantial direct lateral light, no overhead light; $3 \mathrm{a}=$ little direct overhead light; $3 \mathrm{~b}=$ substantial direct overhead light; $4=$ more than $90 \%$ of crown receives full overhead direct light; and $5=$ full overhead and lateral, direct light. CE values of all trees at both sites were estimated by the same researcher (R. J. W. B.). Note that these estimates are only gross indications for differences in light levels between sites, and that actual light levels for trees in the dry site are possibly higher in the same CE class compared to the moist site as crown structure in the dry site is opener (cf. Holbrook et al. 1995).

We related crown exposure to DBH using multinomial logistic regressions (Poorter et al. 2005) for each site separately and tested for differences between sites in these relations. We then tested for differences in DBH growth (over past 5 years) among CE classes, using a multiple regression with log-transformed growth data in which CE classes were entered as dummy variables and average DBH as a covariate. All statistical analyses were performed in SPSS 15.0.
Detecting periods of suppressed growth

We investigated whether juveniles (i.e. pre-canopy trees smaller than 15 or $30 \mathrm{~cm}$ in diameter) in the two forest types differed in frequency and duration of suppressions until reaching the canopy (hypothesis 1). As we were interested in light-related suppressions we established a threshold below which growth is likely suppressed based on light-growth relationships. We considered that individuals with a $\mathrm{CE}$ of 2 (some direct lateral light, but no overhead direct light) were suppressed, while those with a $\mathrm{CE}$ of 3 or higher were not. We set a growth threshold to the value halfway between the median growth at CE2 and that at CE3 (cf. Canham 1985; Landis and Peart 2005), using 5 -year average growth rates to minimize the effect of yearto-year climatic variation.

We identified periods of suppressed growth when growth was below the threshold for at least 5 years (cf. Canham 1985; Landis and Peart 2005). We used sitespecific thresholds to account for differences between sites in light responses. Clearly, when site-specific thresholds strongly differ between sites, this may generate variation in calculated suppressions between sites. We therefore checked the robustness of these results by repeating the suppression calculations using a threshold that is independent of light conditions or light-diameter relations. This alternative threshold is the 25th percentile of all growth rates of juvenile trees (cf. Baker and Bunyavejchewin 2006).

Detecting release events

We investigated whether the number and strengths of growth releases experienced by juvenile trees differed between forest types (hypothesis 1). To detect growth releases we used relative growth increases, which have proven to be reliable indicators of the occurrence of canopy openings in temperate and tropical trees (Nowacki and Abrams 1997; Rubino and McCarty 2004; Baker and Bunyavejchewin 2006). We used moving averages to remove long-term size growth relationships and year-toyear variation on growth rates caused by weather variation. A window of 10 years was applied to calculate the percentage growth change between subsequent 10-year growth periods using the formula of Nowacki and Abrams (1997): $\% \mathrm{GC}_{i}=\left[\left(M_{2}-M_{1}\right) / M_{1}\right] \times 100$, where $\% \mathrm{GC}_{i}=$ percentage growth change for year $1, M_{1}=$ the preceding 10-year mean diameter growth (including year of change), and $M_{2}=$ the subsequent 10-year mean diameter growth. We regarded a growth increase of more than $100 \%$ as a growth release (cf. Brienen and Zuidema 2006), under the condition that growth rates were above the suppression threshold. Such a relative growth threshold may lead to 
biases as they depend on prior growth rates and thus may discriminate against fast-growing trees (cf. Black and Abrams 2003).

We checked for synchronously occurring suppressions and releases, by calculating the proportion of trees with suppressions or releases that started in the same year $( \pm 1)$. We checked whether synchronous suppressions and releases could be related to rainfall or temperature. To this end, we correlated average growth rates to rainfall and temperature.

\section{Canopy accession patterns}

To compare growth trajectories by which trees reach the canopy between forest types (hypothesis 2), we classified trees into "canopy accession patterns" based on the occurrence and frequency of release events and suppressed growth periods (cf. Baker and Bunyavejchewin 2006; Brienen and Zuidema 2006). Such patterns are usually interpreted in terms of temporal variation in light availability, as releases and suppressions are generally not caused by climatic fluctuations. Still, changes in climatic conditions that last for multiple years, or lag effects of climatic fluctuations on growth may occur. Such "climate-induced" releases and suppressions were excluded from the analysis of canopy accession patterns (cf. Results section). Each tree was classified into one of the following three canopy accession patterns:

1. "Direct growth". This pattern corresponds to trees that did not experience periods of suppressed growth that were followed by a release event. These trees were probably not strongly released from dark understorey conditions, and may have been in favourable light conditions early in their life.

2. "One suppression-release pattern". This corresponds to trees that experienced one period of suppression directly followed by a release event. Trees with such a pattern probably did experience strong release from a dark understorey position through canopy dynamics.

3. "Multiple suppression-release pattern". This corresponds to trees that went through several suppressionrelease cycles. These trees required several high-light periods before attaining the canopy.

Persistent growth variation and ages on reaching the canopy

We evaluated to what extent growth variation among trees persists over time (hypothesis 3 ). To this end, we calculated Spearman rank correlations between mean growth rates in pre-canopy size classes and those in successive size classes of 5-cm width [cf. "among-tree autocorrelation" in Brienen et al. (2006)]. To facilitate comparison between sites, we relate correlation coefficients at a similar position in the canopy, i.e. at a similar CE index (cf. Fig. 1). Finally, we reconstructed lifetime growth (size-age) trajectories for all trees and evaluated age variation (coefficient of variation; $\mathrm{CV}$ ) on reaching the canopy in both sites.

\section{Results}

\section{Light profiles}

Crown exposure increased with increasing DBH in both forests in a similar fashion (Fig. 1). The multinomial logistic regressions closely followed the relation between DBH and CE in both forests, with DBH explaining more of the variation in $\mathrm{CE}$ in the moist forest than in the dry forest (Nagelkerke- $R^{2} 0.61$ vs. 0.50). Variation in crown exposure was lower in the dry forest, ranging from CE2b (some direct light) to CE5 (full overhead and lateral, direct light), compared to a range of CE1 (no direct light) to CE5 in the moist forest. Size variation of trees with the same crown exposure was also lower in the dry forest. At the same $\mathrm{DBH}$, trees in the dry forest had a higher crown exposure than those in the moist forest, as indicated by a significant site-effect when CE and DBH data were combined in the multinomial regression $\left(n=282\right.$; Nagelkerke- $R^{2}=0.65$; $P<0.001)$.

Influence of light on growth, and suppressed growth threshold

Diameter growth rates were significantly related to $\mathrm{CE}$ in both forest sites (multiple regression, $P<0.05$ ), while diameter did not enter in the regression equations



Fig. 1 Relationship between crown exposure and average diameterlight relations of Cedrela odorata trees in a dry forest site $(n=153)$ and a moist forest site $(n=129)$. The average diameter-light relations are based on multinomial regressions and differed significantly between forest types $(P<0.001)$. Vertical lines indicate the diameter at which trees reach the canopy 
Fig. 2 Diameter growth rate of C. odorata trees in relation to crown exposure class in a dry and $\mathbf{b}$ moist forest site. Growth rates are averages based on the last five rings (years) of extant trees. Boxes denote 25, 50 (median) and $75 \%$ percentiles; whiskers denote 10 and $90 \%$ percentiles, separate points denote outliers. Letters indicate significant differences $(P<0.05)$ between crown exposure index categories using multiple linear regressions on log-transformed 5 -year median growth rate data. Threshold values for defining suppressions are indicated by arrows

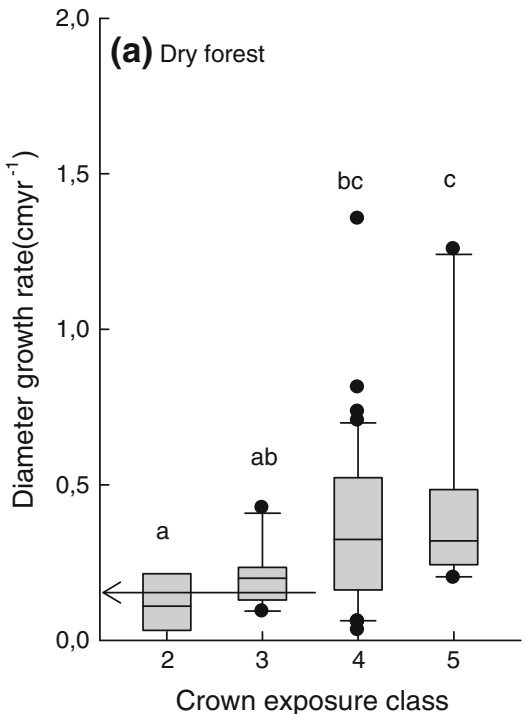

$(P>0.15)$. Partial correlations confirmed this pattern: while diameter growth was significantly correlated to $\mathrm{CE}$ when correcting for diameter $(P<0.001)$, growth was not correlated to diameter after taking its relation to $\mathrm{CE}$ into account $(P>0.05)$. As expected, the proportion of variation in tree growth explained by canopy exposure was higher in the moist forest (dry, $R^{2}=0.21$; moist, $R^{2}=0.35$ ). Growth rates increased with CE in both forests (Fig. 2). In the dry forest, growth rates in CE2 differed significantly with those in CE4 and CE5, and growth in CE3 with that in CE5 $(P<0.05)$. Growth in CE2 and CE3 differed marginally $(P=0.071)$. In the moist forest, growth differed significantly among all $\mathrm{CE}$ classes $(P<0.05)$.

Based on these results, we set threshold values for detecting suppressed growth periods in our ring series to $0.381 \mathrm{~cm}$ year ${ }^{-1}$ for the dry forest and $0.156 \mathrm{~cm}_{\text {year }}{ }^{-1}$ for the moist forest. These thresholds correspond to the midpoint between the median growth rates for CE2 and CE3 (Fig. 2). Note that we did not apply diameter-dependent thresholds as diameter did not influence growth after accounting for the effect of light (i.e. crown exposure). The alternative threshold values - the 25th percentile of precanopy growth data-were almost equal for both forests: 0.190 and $0.184 \mathrm{~cm} \mathrm{year}^{-1}$, for dry and moist forest, respectively.

Suppressed growth, release events and canopy accession patterns

Examples of lifetime growth trajectories of two trees from the dry and two from the moist forest are shown in Fig. 3. The trajectories show high temporal variation in growth rates over the lifetime of individual trees and a large variation among different individuals. Cedrela trees in the two forests differed strongly in the number and intensity of suppressions they experienced before reaching the canopy (Table 2; Fig. 4). In the dry forest a much lower proportion of trees experienced suppressions compared to the moist forest. The median number of suppressions per tree until reaching canopy size and the frequency of suppressions were also much lower in the dry forest. Large differences were also found in the duration of suppressed growth periods (Fig. 4), being nearly half as long in the dry forest. In the dry site suppressions did not exceed 10 years, whereas in the moist site suppressions of up to 58 years were found. We found similarly large differences in the percentage of time that trees were suppressed until reaching the canopy (Fig. 4). Differences between forests in the duration of suppressions and the percentage of time in suppressions were highly significant (Mann-Whitney tests, $P<0.001$ ).

Observed differences in suppressed growth between forests were robust to changes in threshold values. Using the alternative threshold value (25th percentile of pre-canopy growth), differences in suppressions between sites were maintained (Table 2).

Our test of synchronously occurring suppressions did not reveal clear evidence of climate-induced suppressions. The maximum proportion of synchronous suppressions was low in both sites (dry, 12\%; moist, 16\%). Releases in the moist site also did not occur simultaneously, and a maximum of $15 \%$ of releases occurred in the same year $( \pm 1)$. However, we did find a high proportion of concurrent releases: in the dry site $79 \%$ of the trees exhibited releases between 1972 and 1976. These releases represented $48 \%$ of all observed growth spurts. They concurred with a sharp decrease in maximum temperatures between 1969 and 1979 (Fig. S2). A negative correlation between ring width and maximum temperature (Pearson $r=-0.48, P<0.001$ ) over 1950 2004 explains why growth rates increased in the 1970s. Ring width also correlated with rainfall during the rainy 
Fig. 3 Examples of lifetime growth trajectories of $C$. odorata in two forests: a dry forest, direct growth; b moist forest, one suppression-release; c dry forest, one suppression-release; and d moist forest, multiple suppression-release. Threshold values for detecting suppressed growth periods are indicated by horizontal dashed lines, periods of suppression by shaded areas and release events by arrows. The vertical lines indicate age on reaching the canopy (i.e. at 15 and $30-\mathrm{cm}$ diameter for dry and moist forests, respectively)
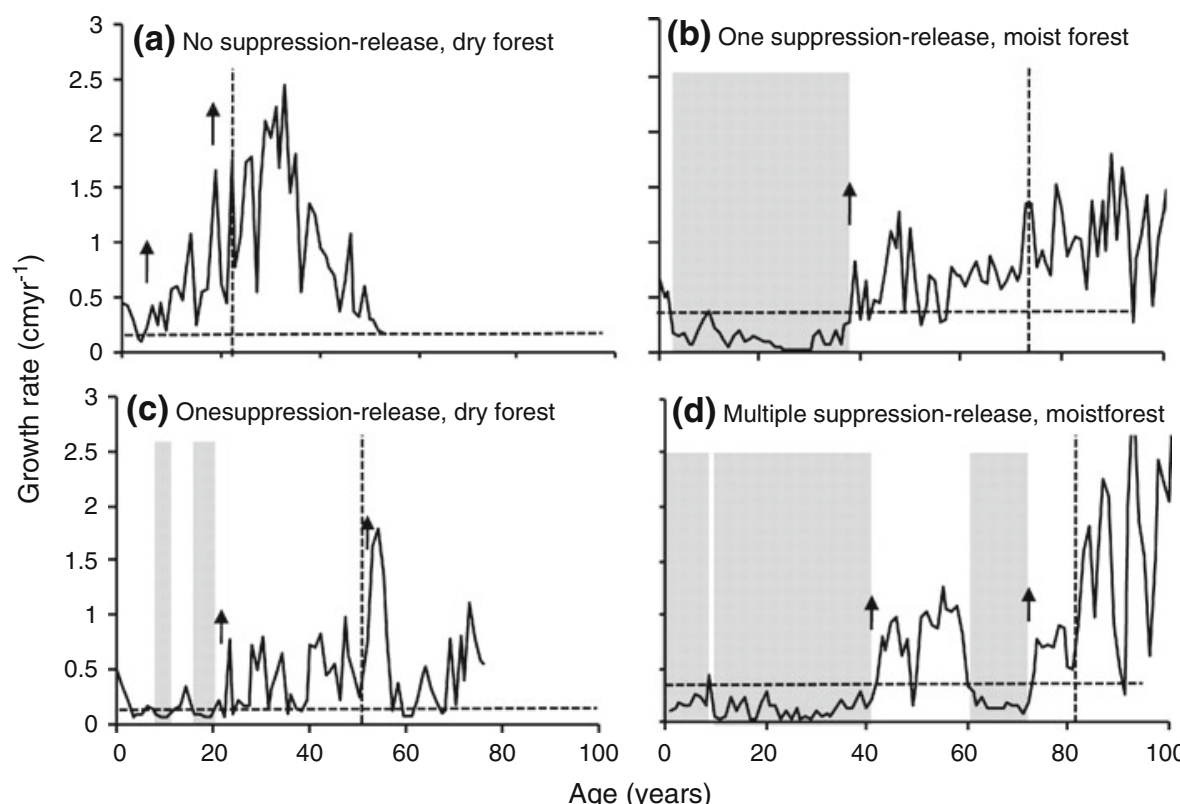

(d) Multiple suppression-release, moistforest

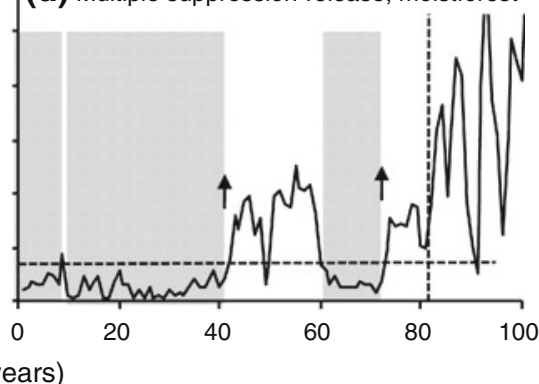

Table 2 Suppressions of $C$. odorata trees in a dry and a moist forest site, applying two growth thresholds: growth suppressed at low light (crown exposure index $=2$; Fig. 2), or growth suppressed below the 25 th percentile growth of all juvenile trees

\begin{tabular}{|c|c|c|c|c|c|c|}
\hline \multirow[t]{2}{*}{ Growth threshold applied } & \multicolumn{3}{|l|}{ Low light } & \multicolumn{3}{|c|}{25 th percentile growth } \\
\hline & $\begin{array}{l}\text { Dry forest } \\
(n=54)\end{array}$ & $\begin{array}{l}\text { Moist forest } \\
(n=74)\end{array}$ & $P$-level & $\begin{array}{l}\text { Dry forest } \\
(n=54)\end{array}$ & $\begin{array}{l}\text { Moist forest } \\
(n=74)\end{array}$ & $P$-level \\
\hline Threshold value $\left(\mathrm{cm}\right.$ year $\left.{ }^{-1}\right)$ & 0.156 & 0.385 & & 0.190 & 0.184 & \\
\hline Trees with one or more suppression (\%) & $17 \%$ & $72 \%$ & $* * *$ & $26 \%$ & $51 \%$ & $*$ \\
\hline Median number of suppressions (max.) & $0(2)$ & $1(6)$ & $* * *$ & $0(2)$ & $1(5)$ & $* *$ \\
\hline $\begin{array}{l}\text { Median frequency of suppressions } \\
\text { per decade (max.) }\end{array}$ & $0(0.71)$ & $0.23(0.78)$ & $* * *$ & $0(0.40)$ & $0.12(0.48)$ & $*$ \\
\hline Median length of suppression (max.) & $5(9)$ & $9(58)$ & $* * *$ & $6(10)$ & $8(47)$ & $*$ \\
\hline $\begin{array}{l}\text { Median percentage of time } \\
\text { suppressed (max.) }\end{array}$ & $0 \%(36 \%)$ & $24.4 \%(75 \%)$ & $* * *$ & $0 \%(39 \%)$ & $5.3(54 \%)$ & $*$ \\
\hline
\end{tabular}

Fisher exact tests were used to test for differences between sites in the percentage of trees with one or more suppressions and Mann-Whitney tests for all other cases

$* P<0.05, * * P<0.005, * * * P<0.001$

season (May-July, $r=0.35, P<0.05$ ), but there were no particular increases in rainfall during the 1970s that may explain increased growth in this period. The simultaneous occurrence of releases and the negative temperature-growth correlation suggest that these releases were climate-induced and not due to canopy dynamics.

After excluding the climate-induced releases between 1972 and 1976, the portion of trees showing releases in the dry forest $(41 \%)$ was nearly half of that in the moist forest (Table 3). Also, dry forest juveniles experienced fewer releases until reaching the canopy, they showed a lower frequency of releases per decade, and the release strength was much weaker (Table 3).

The typical growth trajectory by which trees reach the canopy—the canopy accession pattern-also differed strongly between forest types. The proportion of trees assigned to each of the canopy accession patterns differed significantly between sites (Table 4). In the dry forest, the majority of trees (89\%) reached the canopy through direct growth while only a few (11\%) showed suppression followed by release. No multiple suppression and release patterns were observed in the dry forest. Including climateinduced releases in the dry forest only slightly changed these results (84\% direct growth, $15 \%$ suppression-release). By contrast, in the moist forest, the majority of trees showed one $(41 \%)$ or more $(23 \%)$ suppression-release events. The time to reach the canopy differed significantly between sites and canopy accession patterns (two-way ANOVA, $\left.F_{\text {site }}=30.7, F_{\text {patterns }}=43.8, P<0.001\right)$. On average, trees that showed direct growth reached the canopy 

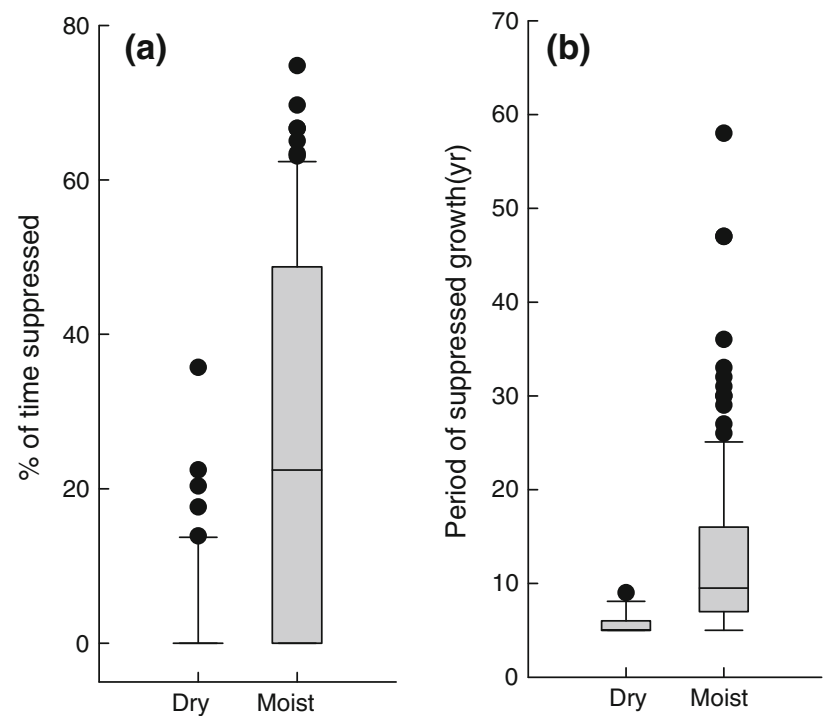

Fig. 4 a Percentage time suppressed and $\mathbf{b}$ duration of suppressed growth periods for $C$. odorata juvenile trees in a dry and a moist forest. Bars indicate $90 \%, 75 \%$, median, $25 \%$ and $10 \%$ percentiles, separate points are outliers. Sample sizes: $n_{\text {Dry }}=54, n_{\text {Moist }}=74$

Table 3 Releases for C. odorata in a dry and a moist forest site

\begin{tabular}{llll}
\hline & $\begin{array}{l}\text { Dry forest } \\
(n=54)\end{array}$ & $\begin{array}{l}\text { Moist forest } \\
(n=74)\end{array}$ & $P$-level \\
\hline $\begin{array}{c}\text { Trees with one } \\
\text { or more release (\%) }\end{array}$ & $41 \%$ & $76 \%$ & $* * *$ \\
$\begin{array}{c}\text { Median number } \\
\text { of releases (max.) }\end{array}$ & $0(2)$ & $1(4)$ & $*$ \\
$\begin{array}{c}\text { Median frequency } \\
\text { of releases } \\
\text { per decade (max.) }\end{array}$ & $0(0.53)$ & $0.17(0.58)$ & $*$ \\
$\begin{array}{c}\text { Median strength (GI) } \\
\text { of release (SD) }\end{array}$ & $174 \%(63 \%)$ & $293 \%(185 \%)$ & $*$ \\
\hline
\end{tabular}

Fisher exact tests were used to detect differences in the percentage trees with one or more releases, and Mann-Whitney tests for all other cases Climate-induced releases at the dry site were excluded

$* P<0.05, * * * P<0.001$

faster (dry, 31 years; moist, 43 years) compared to those that underwent one suppression-release sequence (dry, 46 years; moist, 60 years), while trees experiencing multiple suppression-release cycles took longest to reach the canopy (moist, 84 years).

Persistence of growth variation

The degree to which growth variation among trees was sustained over size classes differed considerably between sites (Fig. 5) In the dry forest, ranking of individuals according to their growth rates in the smallest size class $(0-5 \mathrm{~cm})$ was maintained up to the last size class of $35-40 \mathrm{~cm}$ in diameter (i.e. over $>64$ years), whereas in the moist forest ranking generally disappeared in the subsequent size classes (i.e. after 12 years). Also for larger size classes, we found that growth differences in the dry forest site were maintained longer and over more size classes. Hence, in the dry forest, a relatively fast-growing sapling was also likely to grow fast as an adult, which was much less likely to be the case for saplings in the moist forest site, where such juvenile trees change more frequently in growth rank. These differences were not caused by between-site differences in passage time from one size class to another as these were comparable.

\section{Variation in age on reaching the canopy}

The age-size variation for both sites is shown in Fig. 6 . Both maximum age and mean age on reaching the canopy were higher in moist forest compared to dry forest (Table 2). However, mean age at a given diameter was remarkably similar for both forest types, and so was the degree of age variation among individuals $(\mathrm{CV}=33 \%$ in dry and $34 \%$ in moist forest).

\section{Discussion}

Attaining the canopy in dry and moist forests

Our results support hypothesis 1 that trees in the moist forest experience more and longer suppressions and more and stronger releases during their growth into the canopy than trees in the dry forest. The observed differences were large, with trees in the moist forest experiencing 4 times more suppressions and 2 times more releases. These differences were robust to the application of different growth thresholds. It is important to note that they were not due to the longer trajectory towards the canopy in the moist forest, as they were maintained when expressed as the proportion of time suppressed, or the frequency of suppression or release events. Canopy accession patterns were also very distinct. In the moist forest a high percentage of trees (64\%) required one or several releases from suppressions, whereas only a small portion in the dry forest trees $(11 \%)$ showed such patterns. Taken together, these results suggest that light is a stronger limiting factor in the moist forest and that releases from low-light conditions are more important for trees in the moist forest compared to the dry forest.

The fact that $40 \%$ of juvenile trees still showed releases suggests a role of gap formation in dry forests. One characteristic of dry-forest gaps may be relevant in this respect. For a given gap width, the amount of direct light received close to the forest floor is probably higher in dry forests 
Table 4 Canopy accession patterns of $C$. odorata trees in a dry and a moist forest

\begin{tabular}{|c|c|c|c|c|}
\hline \multirow[t]{2}{*}{ Canopy accession pattern } & \multicolumn{2}{|c|}{ Dry forest $(n=54)$} & \multicolumn{2}{|c|}{ Moist forest $(n=74)$} \\
\hline & $\begin{array}{l}\text { Percentage } \\
\text { of trees }(\%)\end{array}$ & $\begin{array}{l}\text { Mean time to } \\
\text { reach } 15 \mathrm{~cm} \\
\text { (year, range) }\end{array}$ & $\begin{array}{l}\text { Percentage } \\
\text { of trees }\end{array}$ & $\begin{array}{l}\text { Mean time to } \\
\text { reach } 30 \mathrm{~cm} \\
\text { (year, range) }\end{array}$ \\
\hline Direct growth & 89 & 30.8 a $(9-59)$ & $36 \%$ & 42.9 a $(27-70)$ \\
\hline One suppression-release & 11 & $46.3 \mathrm{~b}(36-55)$ & $41 \%$ & 60.1 b (37-90) \\
\hline Multiple suppression-release & 0 & - & $23 \%$ & $84.3 \mathrm{c}(67-122)$ \\
\hline All trees & & 35 A (9-59) & & 61 B (27-122) \\
\hline
\end{tabular}

The distribution of trees over canopy accession patterns differed between sites (Fisher exact test, $P<0.001$ ). The time to reach the canopy varied among accession patterns and sites Climate-induced releases at the dry site were excluded

Two-way ANOVA, Bonferroni post hoc tests, different letters indicate differences between accession patterns or sites (capital letters), $P<0.05$

Fig. 5 Rank correlations (Spearman's $\rho$ ) showing persistence of growth variation between $C$. odorata trees in juvenile classes and larger size classes, in a dry (a, $\mathbf{c}$ and, $\mathbf{e})$ and moist forest (b, $\mathbf{d}$ and $\mathbf{f}$ ) site. Shaded bars represent significant correlations $(P<0.05)$. For clarity, correlations of juveniles in some categories are not shown, but results are comparable with those shown. Sample sizes: $n_{\text {Dry }}=15-67$, $n_{\text {Moist }}=44-71$



(b) 0-5 with ...



(d) 10-15 with ...
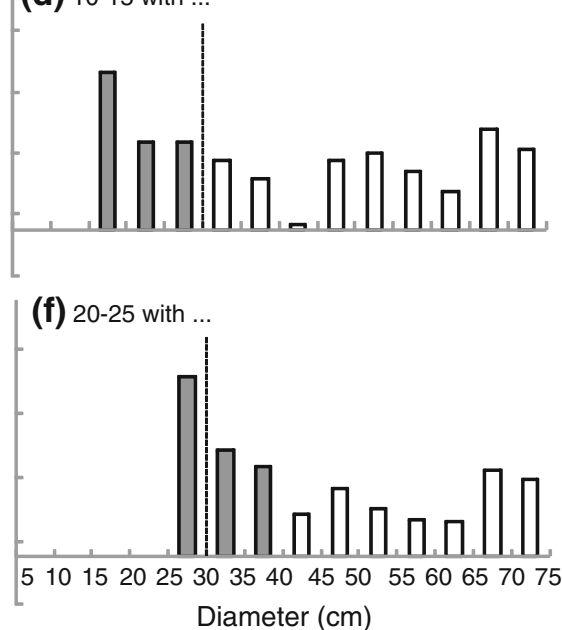

compared to moist forests as the surrounding canopy is much lower. On the other hand, dry-forest gaps are probably smaller as trees often die standing (Segura et al. 2003) and are shorter (Holbrook et al. 1995). In comparison, moist forest trees often die uprooted or snapped thereby forming large $\left(>300 \mathrm{~m}^{2}\right.$ ) gaps (Martínez-Ramos et al. 1988a; Brokaw 1996). Such large gaps take a long time (>10 years) to close (Martínez-Ramos et al. 1988b; van der Meer and Bongers 1996). Also, gap closure in moist forests may take longer as the forest is taller. In all, we argue that in moist forests, differences in light levels between gaps and understorey are larger and that gaps close more slowly. These contrasting canopy dynamics may explain why $\mathrm{Ced}$ rela juvenile trees experienced longer suppressions and stronger releases in the moist forest. Combining these results with the light-demanding nature of our study species, one may suggest that juvenile Cedrela trees in the dry forest establish in gaps and are then able to reach the canopy before the gap closes. By contrast, juvenile trees that establish in gaps in moist forests take more time to reach the canopy and may thus experience closure of the canopy and suppressed growth resulting from this. This comparison needs to be made cautiously, though, as the (generally) larger canopy gaps in moist forests probably close more slowly.

Interestingly, half of the growth releases in the dry forest occurred synchronously and coincided with a considerable drop in maximum temperatures in the 1970s. The negative 
Fig. 6 Age-diameter relationships of $C$. odorata trees in a dry and $\mathbf{b}$ moist forest site. Each line represents the lifetime growth trajectory of an individual tree. Arrows indicate the age variation on reaching the canopy, i.e. $15-\mathrm{cm}$ diameter for the dry and $30-\mathrm{cm}$ diameter for the moist forest. Sample sizes: $n_{\text {Dry }}=69$, $n_{\text {Moist }}=79$


correlation between temperature and growth rate suggests that these releases were indeed induced by periodic change in climatic conditions. Several studies have shown lower diameter growth rates of tropical trees at higher temperature, as a result of lower photosynthesis rates, increased respiration or drought stress (Clark et al. 2003; Fichtler et al. 2004; Feeley et al. 2007). The climate-induced releases that we observed may have been caused by either of these causes, or their combined effect. It is interesting to note that climate-induced releases were not observed in the moist forest, as indicated by the low portion of simultaneous releases. Whether this is due to lower drought stress in the moist forest, or differences in the degree of climatic variation between sites, remains to be studied. The finding of climate-induced releases shows that climate variability may also influence long-term growth patterns, and this effect needs to be taken into account in release-suppression studies (cf. Rubino and McCarty 2004).

Can differences in growth trajectories between forest types be expected for more tree species? The differences in understorey light levels between dry and moist forests (Holbrook et al. 1995; Coomes and Grubb 2000) certainly may give rise to distinct growth patterns for other tree species. It is likely that species with light requirements similar to those of Cedrela will also show fewer and shorter periods of suppression in dry forests compared to moist forests. We expect that for such species, the importance of suppression-release cycles decreases towards drier forests.

The observed difference in canopy accession across forest types may have important demographic consequences (cf. Smith and Huston 1989; Zuidema et al 2009). Cedrela trees in the moist forest clearly have less favourable gap regeneration opportunities and take longer to reach the canopy. Thus, assuming similar juvenile mortality, cumulative survival to reproductive size (which is typically attained on reaching the canopy) may be low, compared to that in the dry forest. This limitation may be offset by a longer life span of trees in the moist forest (cf. Table 1) resulting in higher reproductive output (e.g. Zuidema and Boot 2002).
Thus, moist-forest populations are likely maintained in a different way than dry-forest populations, and may give rise to variation in life history strategies of the same species in contrasting forest types. Clearly, a thorough analysis of the life history consequences of our results requires a demographic study that includes all vital rates of all life stages.

Determinants of long-term growth variation

In accordance with our expectations, growth differences among saplings persisted over longer time spans in the dry forest than in the moist forest. Sites were strikingly distinct in this respect: in the dry forest, growth rate differences between saplings persisted until they reached adult size (i.e. over 64 years), whereas growth rate differences in the moist forest disappeared relatively rapidly (after 12 years). The long persistence of growth differences in the dry forest is consistent with the expected consequences of strong spatial heterogeneity in water availability on growth variation among trees. Differences in water availability likely have a life-long impact on tree growth while the effect of temporal variation in light availability due to canopy dynamics is typically limited to periods of one or two decades (van der Meer and Bongers 1996; Brienen and Zuidema 2005). Although heterogeneity in other resources like nutrients may also cause part of the observed persistent growth differences among trees in dry forests, the effect of soil water availability on growth is probably much larger (Medina 1995; Mooney et al. 1995; Oliveira-Fihlo et al. 1998). In moist forests, effects of soil type and water availability on tree growth rate (Ashton et al. 1995; Gunatilleke et al. 1998; Baker et al. 2003b) are probably less influential than temporal variation in light, particularly for light-demanding canopy tree species. In the case of Cedrela, the very distinct growth patterns in different forest types yielded the same degree of variation in ages. This is probably a coincidence, as sitespecific growth patterns likely cause differences in age variation among forest types. 
Canopy accession and maintenance of tree diversity in dry and moist forests

Gap dynamics play a central role in theories on niche differentiation and maintenance of biodiversity (Grubb 1977; Ricklefs 1977). These theories have been developed mostly based on processes in wet tropical forests (eg. Denslow 1980; Brokaw 1985; Turner 2001) and are thought not to apply to dry forests (Mooney et al. 1995). However, this assertion had not been tested so far. By comparing canopy accession of trees in dry and moist forests, our study represents a first step by showing that growth trajectories of trees of the same species vary strongly between forest types. If these differences are indeed caused by the differences in the importance of gap formation, it implies that gap dynamics impose less selection pressure on trees in the dry forest. The main environmental gradient in dry forests seems to be spatial heterogeneity in soil water and nutrients (Murphy and Lugo 1986; Mooney et al. 1995; Ceccon et al. 2006). However, even in wet forests spatial heterogeneity in water plays a role (Ashton et al. 1995; Baker et al. 2003b) and even in dry forests light availability determines species distribution to a small degree (OliveiraFilho et al. 1998). Hence, we expect a gradual shift with light variation becoming less important towards drier forests and spatial heterogeneity in water availability becoming less important in wetter forests (cf. Engelbrecht et al. 2007). Differences in the relative importance of these basic resources for tree growth (light and water) probably suggest that mechanisms of species diversity maintenance vary across tropical forest types.

The approach used here-to study the same species in contrasting forest types and apply a combination of long-term tree ring data and field measurements on light conditions-proved to be successful. Similar analyses need to be undertaken for more species and at more sites to determine how climate and forest structure interact to shape growth trajectories of juvenile trees. Results of such studies will improve the understanding of tree demography, forest dynamics and diversity patterns across tropical forest types.

Acknowledgments We thank the field teams of PROMAB and Ejido Pich, in particular Ramiro Camara, for their invaluable help during sampling. Eva Stadtler for help with the ring measurements, Diego Perez-Salicrup for the use of the VELMEX measurement table, and Leonel Lopéz for providing the data on basal area of the Mexican study site. Patrick Baker, Tim Baker, Bettina Engelbrecht, Danaë Rozendaal and two reviewers provided valuable comments on an earlier version of the manuscript. R. J. W. B. acknowledges the Dirección General de Asuntos del Personal Académico of UNAM for his postdoctoral grant. Our study complies with the current laws of the countries in which the research was conducted.
Open Access This article is distributed under the terms of the Creative Commons Attribution Noncommercial License which permits any noncommercial use, distribution, and reproduction in any medium, provided the original author(s) and source are credited.

\section{References}

Ashton PMS, Gunatilleke CVS, Gunatilleke IAUN (1995) Seedling survival and growth of four Shorea species in a Sri Lankan rainforest. J Trop Ecol 11:263-279

Baker PJ, Bunyavejchewin S (2006) Suppression release and canopy recruitment in five tree species from a seasonal tropical forest in western Thailand. J Trop Ecol 22:521-529

Baker TR, Swaine MD, Burslem DFRP (2003a) Variation in tropical forest growth rates: combined effects of functional group composition and resource availability. Perspect Plant Ecol Evol Syst 6:21-36

Baker TR, Burslem DFRP, Swaine MD (2003b) Associations between tree growth soil fertility and water availability at local and regional scales in Ghanaian tropical rain forest. J Trop Ecol 19:109-125

Brienen RJW, Zuidema PA (2005) Relating tree growth to rainfall in Bolivian rain forests: a test for six species using tree ring analysis. Oecologia 146:1-12

Brienen RJW, Zuidema PA (2006) Lifetime growth patterns and ages of Bolivian rain forest trees obtained by tree ring analysis. J Ecol 94:481-493

Brienen RJW, Zuidema PA, During HJ (2006) Autocorrelated growth of tropical forest trees: unravelling patterns and quantifying consequences. For Ecol Manag 237:179-190

Brienen RJW, Lebrija-Trejos E, van Breugel M, Perez-Garcia EA, Bongers F, Meave JF, Martinez-Ramos M (2009) The potential of tree rings for the study of forest succession in southern Mexico. Biotropica 41:186-195

Brokaw NVL (1985) Gap-phase regeneration in a tropical forest. Ecology 66:682-687

Brokaw NVL (1996) Treefalls: frequency timing and consequences. In: Leigh EG, Rand AS, Windsor DM (eds) The ecology of a tropical forest: seasonal rhythms and long-term changes. Smithsonian Institution Press, Washington DC, pp 101-108

Bullock SH (1997) Effects of seasonal rainfall on radial growth in two tropical species. Int J Biometeorol 4:13-16

Canham CD (1985) Suppression and release during canopy recruitment in Acer saccharum. Bull Torrey Bot Club 112:134-145

Ceccon E, Huante P, Rincón E (2006) Abiotic factors influencing tropical dry forests regeneration. Braz Arch Biol Technol 49:305-312

Chave J, Andalo C, Brown S, Cairns MA, Chambers JQ, Eamus D, Fölster H, Fromard F, Higuchi N, Kira T, Lescure J-P, Nelson BW, Ogawa H, Puig H, Riéra B, Yamakura T (2005) Tree allometry and improved estimation of carbon stocks and balance in tropical forests. Oecologia 145:87-99

Chazdon RL, Fetcher N (1984) Light environments of tropical forests. In: Medina E, Mooney HA, Vasques-Yanes C (eds) Physiological ecology of plants of the wet tropics. Junk, The Hague, pp 27-36

Clark DA, Clark DB (1992) Life-history diversity of canopy and emergent trees in a Neotropical rain-forest. Ecol Monogr 62:315-344

Clark DA, Clark DB (1999) Assessing the growth of tropical rain forest trees: issues for forest modeling and management. Ecol Appl 9:981-997

Clark DA, Piper SC, Keeling CD, Clark DB (2003) Tropical rain forest tree growth and atmospheric carbon dynamics linked to interannual temperature variation during 1984-2000. Proc Natl Acad Sci 100:5852-5857 
Coomes D, Grubb PJ (2000) Impacts of root competition in forests and woodlands: a theoretical framework and review of experiments. Ecol Monogr 70:171-207

Denslow JS (1980) Gap partitioning among tropical rain forest trees. Biotropica 12:47-55

Dünisch O, Bauch J, Gasparotto L (2002) Formation of increment zones and intraannual growth dynamics in the xylem of Swietenia macrophylla, Carapa guianensis, and Cedrela odorata (Meliaceae). IAWA J 23:101-119

Engelbrecht BMJ, Comita LS, Condit R, Kursar TA, Tyree MT, Turner BL, Hubbell SP (2007) Drought sensitivity shapes species distribution patterns in tropical forests. Nature 447:80-83

Feeley KF, Wright SJ, Supardi MNN, Kassim AR, Davies SJ (2007) Decelerating growth in tropical forest trees. Ecol Lett 10:461-469

Fichtler E, Trouet V, Beeckman H, Coppin P, Worbes M (2004) Climatic signals in tree rings of Burkea africana and Pterocarpus angolensis from semiarid forests in Namibia. Trees 18:442-451

Fowler N (1986) The role of competition in plant communities in arid and semiarid regions. Annu Rev Ecol Syst 17:89-110

Grubb PJ (1977) The maintenance of species-richness in plant communities: the importance of the regeneration niche. Biol Rev 52:107-145

Gunatilleke CVS, Gunatilleke IAUN, Ashton PMS, Ashton PS (1998) Seedling growth of Shorea (Dipterocarpaceae) across an elevational range in Southwest Sri Lanka. J Trop Ecol 14:231-245

Holbrook NM, Whitbeck JL, Mooney HA (1995) Drought responses of Neotropical dry forest trees. In: Bullock SH, Mooney HA, Medina E (eds) Seasonally dry tropical forests. Cambridge University Press, Cambridge, pp 243-246

Holmes RL (1982) Computer-assisted quality control in tree-ring dating and measurement. Tree-Ring Bull 44:69-75

Landis RM, Peart DR (2005) Early performance predicts canopy attainment across life histories in subalpine forest trees. Ecology $86: 63-72$

Martínez-Ramos M, Alvarez-Buylla E, Sarukhán J, Piñero D (1988a) Treefall age determination and gap dynamics in a tropical forest. J Ecol 76:700-716

Martínez-Ramos M, Sarukhán J, Piñero D (1988b) The demography of tropical trees in the context of forest gap dynamics: the case of Astrocaryum mexicanum at Los Tuxtlas tropical rain forest. In: Davy DJ, Hutchings MJ, Watkinson AR (eds) Plant population ecology. Blackwell, Oxford, pp 293-313

Medina E (1995) Diversity of life-forms of high plants in Neotropical dry forests. In: Bullock SH, Mooney HA, Medina E (eds) Seasonally dry tropical forests. Cambridge University Press, Cambridge, pp 221-242

Mooney HA, Bullock SH, Medina E (1995) Introduction. In: Bullock SH, Mooney HA, Medina E (eds) Seasonally dry tropical forests. Cambridge University Press, Cambridge, pp 1-8

Murphy PG, Lugo AE (1986) Ecology of a tropical dry forest. Annu Rev Ecol Syst 17:67-88
Nath CD (2007) Tree diameter growth: variations and demographic niches in a tropical dry forest of southern India. PhD thesis, Centre for Ecological Sciences, Indian Institute of Science, Bangalore

Nath CD, Dattaraja HS, Suresh HS, Joshi NV, Sukumar R (2006) Patterns of tree growth in relation to environmental variability in the tropical dry deciduous forest at Mudumalai southern India. J Biosci 31:651-669

Nowacki GJ, Abrams MD (1997) Radial-growth averaging criteria for reconstructing disturbance histories from presettlement-origin oaks. Ecol Monogr 67:225-249

Oliveira-Filho AT, Curi N, Vilela EA, Carvalho DA (1998) Effects of canopy gaps topography and soils on the distribution of woody species in a central Brazilian deciduous dry forest. Biotropica 30:362-375

Pennington TD, Styles BT (1975) A generic monograph of the Meliaceae. Blumea 22:419-540

Poorter L, Bongers F, Sterck FJ, Wöll H (2005) Beyond the regeneration phase: differentiation of height-light trajectories among tropical tree species. J Ecol 93:256-267

Ricklefs RE (1977) Environmental heterogeneity and plant species diversity: a hypothesis. Am Nat 111:376-381

Rubino DL, McCarty BC (2004) Comparative analysis of dendroecological methods used to assess disturbance events. Dendrochronologia 21:97-115

Segura G, Balvanera P, Durán E, Pérez A (2003) Tree community structure and stem mortality along a water availability gradient in a Mexican tropical dry forest. Plant Ecol 169:259-271

Smith T, Huston M (1989) A theory of the spatial and temporal dynamics of plant communities. Vegetatio 83:49-69

Stahle DW (1999) Useful strategies for the development of tropical tree-ring chronologies. IAWA J 20:249-253

Terborgh J (1992) Diversity and the tropical rain forest. Scientific American Library New York, New York

Turner IM (2001) The ecology of trees in the tropical rain forest. Cambridge University Press, Cambridge

van der Meer PJ, Bongers F (1996) Formation and closure of canopy gaps in the rain forest at Nouragues French Guiana. Plant Ecol 126: $167-179$

Worbes M (1999) Annual growth rings rainfall-dependent growth and long-term growth patterns of tropical trees from the Caparo Forest Reserve in Venezuela. J Ecol 87:391-403

Zuidema PA, Boot RGA (2002) Demography of the Brazil nut tree (Bertholletia excelsa) in the Bolivian Amazon: impact of seed extraction on recruitment and population dynamics. J Trop Ecol 18:1-31

Zuidema PA, Brienen RJW, During HJ, Güneralp B (2009) Do persistently fast-growing juveniles contribute disproportionately to population growth? A new analysis tool for matrix models and its application to rainforest trees. Am Nat 174:709-719 